\title{
Consumers' knowledge and attitude towards Chinese herbal tea and consumption of Chinese herbal tea in selected district in Kedah
}

\author{
Teh, D.Y., *Jaafar, S.N. and Asma', A. \\ Faculty of Fisheries and Food Science, University Malaysia Terengganu, 21030 Kuala Nerus, Terengganu, \\ Malaysia
}

\begin{abstract}
Article history:
Received: 30 September 2019

Received in revised form: 12

November 2019

Accepted: 12 November 2019

Available Online: 30

December 2019
\end{abstract}

\section{Keywords:}

Chinese herbal tea,

Consumer knowledge,

Consumer attitude,

Herbal tea consumption

DOI:

https://doi.org/10.26656/fr.2017.4(3).327

\begin{abstract}
Interest in botanical remedies has attracted growing attention in Chinese herbal teas among industry, scientists and consumers. A survey was conducted among 203 respondents recruited from several Chinese herbal shops in a selected town in Kedah. Data were subjected to obtain descriptive statistics and inferential tests. The results showed that more than half of consumers have moderate knowledge level and almost positive attitude towards Chinese herbal tea. Consumers of different races have a significant difference in knowledge score towards Chinese herbal tea. In addition, consumers' attitude between different age groups was also found to be different. Consumers' gender, race, age, marital status, and employment status were associated with their Chinese herbal tea consumption. This study revealed public' understanding towards knowledge, attitude and consumption towards Chinese herbal tea. It is anticipated that these findings may benefit authorities in policies and regulations development and convey correct information and useful knowledge for the public as well as Chinese herbal tea traders for strategic marketing to meet consumers' demand.
\end{abstract}

\section{Introduction}

Chinese herbal tea is herbal drinks widely produced in southern China and consumed by billions of people worldwide to prevent and treat internal heat as well as a range of associated health conditions (Li et al., 2013). World Health Organization (WHO) estimates that $80 \%$ of the world's population still rely on traditional or herbal medicine and the majority of people in those countries believe that it is safe to use herbal medicine (Hassali et al., 2009). The use of Chinese herbal teas has increased in this recent year other than have been used medicinally for centuries. Recently, they are viewed as natural products and therefore it is safe and healthy alternatives to conventional beverages (Wilson, 1993). However, some herbs have been restricted or banned based on safety regulations. According to Food Nation 2017, for Westerners, the use of Chinese herbal teas was focused on the ancient claims related to weight loss and more modern claims of cancer-prevention because of the antioxidant properties in teas (Chinese Herb Tea, 2017). Majority of ethnic groups in Malaysia population believe that herbal products do not contain harmful chemicals and are free of side effects when compared to commercially available pharmaceutical drugs (Law and Soon, 2013). Many research had shown that Chinese herbal tea function in protecting against cardiovascular disease, cancer, diabetes and Alzheimer's disease (Matic et al., 2013; Daily et al., 2015; Li and Zhu, 2016; Zemestani and Rafraf, 2016). To date, no study has reported on the knowledge, attitude and consumption of Chinese herbal tea in Malaysia. Thus, this study revealed public' understanding towards knowledge, attitude and consumption towards Chinese herbal tea in a town in Kedah, Malaysia.

The growth of Chinese herbal tea has been marked by the Malaysian herbal industry and identified as one of the entry point project (EPP) under the agriculture new key economic areas (NKEA) in the economic transformation programme (ETP) which commenced in early 2011 (Ahmad et al., 2015). Besides that, customer demand continues to grow over the forecast period because consumer wanted to avoid excess consumption of caffeine through coffee and is encouraged to consume more tea as tea helps to boost the immune system and to reduce cholesterol and blood pressure (Jessica, 2011). Although the use of Chinese herbal tea has attracted the attention of consumers in terms of safety and side effects, research regarding Chinese herbal tea has not encompassed an exploration of the knowledge and perception of lay respondents about the use of herbal beverages (Hassali et al., 2009). 
The main objectives of this study are to determine consumers' knowledge and attitude of consumption towards Chinese herbal teas, to compare the knowledge and attitude of Chinese herbal teas with sociodemographic profile and to examine the association between consumers' consumption of Chinese herbal teas and socio-demographic profile. Understanding knowledge and attitude of consumers on Chinese herbal tea could provide baseline data on the research topics which could be beneficial for government and health professionals to educate the public on ways to improve their body health with the aid of Chinese herbal tea.

\section{Materials and methods}

\subsection{Sample size}

This study is a cross-sectional non-experimental research, conducted among selected M40 groups in Sungai Petani in Kedah state. According to the Department of Statistics Malaysia (2010), Kedah had a total population of 1,880,783 in 2010. Based on sample size calculation using the formula of Yamane (1967), initial sample size (n) was 399. Since statistics revealed that citizens with the age of 18 years old and above in Kedah state were $59.69 \%$ of the total population, the sample size (n) for this study is 238 . After data checking and cleaning, data for 203 respondents were proceeded for further analysis.

\subsection{Research instrument}

Data collection was conducted by using the selfadministered questionnaire using closed-ended questions. All questionnaire provided were in English and Malay version. However, the questionnaire in Mandarin version was prepared in case the respondents cannot understand English and Malay.

The questionnaire consists of five sections. Section 1 in the questionnaire was the socio-demographic profile of respondents. There were 7 questions including gender, race, age, marital status, education, occupation, and estimated monthly household income (Lan et al., 2012). The scale used for this session were nominal scale and ordinal scale. Section 2 asked in the questionnaire was consumers' general health concerns. 7 questions related to health status were asked in this session and the scale used was nominal scale and ordinal scale (five-point Likert scale) with 'Definitely true' considered as 1 score while 'Definitely false' considered as 5 scores (Daly et al., 2009). Consumers' knowledge on Chinese herbal tea was asked in section 3 with a total of 20 questions. The nominal scale was used to design the questions with the answer option of 'Yes', 'No' and 'Not Sure'. Each question with 'Yes' answer was considered equivalent to 1 score while 'No' and 'Not Sure' answer did not hold any score. The total knowledge scores were then categorized into three levels which are a low score $(0$ 6), moderate score (7 - 13) and high score (14 - 20) (Nekesa, 2012). The questions were partially adapted and modified from Wilson (1993), Ravikumar (2014), Lin et al. (2013) and Daily et al. (2015).

Consumers' attitude towards Chinese herbal tea was asked in section 4 which consisted of 18 questions included factors influence and reason for consuming Chinese herbal tea ( $\mathrm{Li}$ et al., 2013). The ordinal scale which was five-point Likert scale was used in this session with 'Strongly disagree' was considered as 1 score while 'Strongly agree' was considered as 5 scores. Next, eleven questions on consumption of Chinese herbal tea by consumers were asked in session 5 by using the nominal scale and the preference or ranking scale. Questions in this session included types of Chinese herbal tea consumed, frequency and reason for consuming Chinese herbal tea which was partially modified from Wilson (1993) and Noguchi-Shinohara et al. (2014).

A pilot test was conducted to measure the validity and reliability of the measurement items in the developed questionnaire and to ensure all participants understand the questions (Teijlingen and Hundley, 2002). In specific, reliability test and correlation analysis was conducted specifically for the question using continuous scale i.e. consumer attitudes. Validity test revealed that most of the values for item-to-correlation (ITC) were greater than 0.3, considered to have an acceptable standard for good correlation (Nunnally and Bernstein, 1994) ranging from 0.363 to 0.842 , except for item 17 with ITC value of 0.228 . The ITC value which was less than 0.3 indicated a low correlation with other items. Convergence validity was tested using correlation analysis. It was used to measure the extent of correlation between theoretically related constructs. The $r$ values obtained were referred to Guilford's rule of thumb (Guilford and Fruchter, 1973). With the total of 153 items in the consumers' attitude towards Chinese herbal tea, 90 items were correlated while 63 items were not correlated, showing substantial relationship was detected among items representing 'consumer attitudes'. Therefore, the questions for consumers' attitude towards Chinese herbal tea were accepted with a slight modification to a few items such as item 17 i.e. "I consume Chinese herbal tea to manage my stress" was changed to "I consume Chinese herbal tea when I am stress".

\subsection{Data analysis}

A total of 203 respondents were analysed by using Statistical Package for Social Science (SPSS) version 
20.0 and Minitab. Prior to analysis, all data were tested for normality. The data were assumed to be normal in this study as sample size $>30$ or 40 , and parametric procedures can be used even when the data are not normally distributed as the violation of the normality assumption should not cause a major problem (Ghasemi and Zahediasl, 2012).

Descriptive statistics were obtained for the sociodemographic profile, consumers' knowledge, attitude and consumption towards Chinese herbal tea in this study. Data such as socio-demographic profile, knowledge on Chinese herbal tea and consumers' consumption towards Chinese herbal tea used were presented in frequency (n) and percentage (\%), while consumers' attitude towards Chinese herbal tea was presented in mean and standard deviation. In addition, the scoring system used for consumers' knowledge was one mark given for each correct answer whereas no mark was given to false answer or those marked 'Not sure'.

Furthermore, one-way ANOVA in Minitab was used to determine the consumers' preference in the consumption of Chinese herbal tea. Independent t-test and one-way ANOVA in SPSS were used to compare consumers' knowledge and attitude with the sociodemographic profile. Independent t-test was used for gender while one-way ANOVA was used for races, age, marital status, educational level, and estimated current monthly household income. Furthermore, Chi-square was used to examine the association of consumers' consumption of Chinese herbal tea and socio- demographic profile. There are four assumptions which needed to fulfil before using this test. The significance value was set at 0.05 for all statistical analysis for this study.

\section{Results and discussion}

\subsection{Socio-demographic profile}

A total of 203 survey questionnaires were distributed through purposive sampling and quota sampling. Types of the analyses that covered in this chapter were descriptive statistics and inferential statistics which consisted of independent t-test, one-way ANOVA and Chi-square. Table 1 shows the socio-demographic profile of respondents involved in the present survey.

From the total of 203 respondents, 82 respondents were male $(40.4 \%)$ and 121 respondents were female $(59.6 \%)$, which consisted of Chinese respondents (81.8\%), Malay respondents (17.2\%) and Indian respondents $(0.5 \%)$. For gender percentage, the survey respondents were more likely to be female. However, the Department of Statistics Malaysia (2017) stated that the male population is outnumbered the female population with 107 males per 100 females in 2017. The contrast of gender percentage may be explained by the previous study which showed that female had greater willingness to participate in the survey compared to male with a greater proportion of $58 \%$ versus $51 \%$ and yet it depended on the survey topic (Amundsen, 2013; Glass et al., 2015). For races, most of the customers in Chinese herbal shops were Chinese, thus the majority of the

Table 1. Socio-demographic profile of the respondents

\begin{tabular}{|c|c|c|c|}
\hline & Demographic factors & $\begin{array}{l}\text { Frequency } \\
(\mathrm{n}=203)\end{array}$ & Percentage $(\%)$ \\
\hline \multirow{2}{*}{ Gender } & Male & 82 & 40.4 \\
\hline & Female & 121 & 59.6 \\
\hline \multirow{4}{*}{ Races } & Malay & 35 & 17.2 \\
\hline & Chinese & 166 & 81.8 \\
\hline & Indian & 1 & 0.5 \\
\hline & Others & 1 & 0.5 \\
\hline \multirow{5}{*}{ Age } & $18-25$ years old & 69 & 34 \\
\hline & $26-35$ years old & 21 & 10.3 \\
\hline & $36-45$ years old & 30 & 14.8 \\
\hline & 46 - 55 years old & 47 & 23.2 \\
\hline & 56 years old and above & 36 & 17.7 \\
\hline \multirow{3}{*}{ Marital status } & Single & 87 & 42.9 \\
\hline & Married & 107 & 52.7 \\
\hline & Divorced/ Widowed & 9 & 4.4 \\
\hline \multirow{5}{*}{ Employment status } & Employed & 109 & 53.7 \\
\hline & Not working/ housewife & 16 & 7.9 \\
\hline & Self-employed/ Own business & 20 & 9.9 \\
\hline & Retired & 24 & 11.8 \\
\hline & Student & 34 & 16.7 \\
\hline
\end{tabular}

Descriptive analysis was used. 
respondents in this study were Chinese. However, statistics showed the population of Chinese residents $(23.9 \%)$ in Kedah was less than Malay residents (57.1\%) (Department of Statistics Malaysia, 2010).

Result showed that the highest age range of respondents obtained in this survey was from 18 to 25 years old (34\%), followed by 46 to 55 years old $(23.2 \%)$, 56 years old and above $(17.7 \%)$ and 36 to 45 years old $(14.8 \%)$ while the lowest age range of respondents in this survey was from 26 to 36 years old $(10.3 \%)$. This situation may due to the willingness to participate in the study. People aged from 18 to 25 years old were more willing to participate in the study than people aged from 26 to 36 years old which were rushing their time back to the workplace after purchasing from Chinese herbal shop and not willing to participate in the study. A total of $53.7 \%$ respondents were employed while $16.7 \%$ of respondents were students and $11.8 \%$ of respondents were retired.

\subsection{Level of consumers' knowledge and attitude towards Chinese herbal tea}

Consumers' knowledge towards Chinese herbal tea was categorized into three levels which are low $(0-6)$, moderate (7 - 13) and high (14 - 20) (Nekesa, 2012). The total scores of correct answers responded by each respondent were summed up and converted into percentage. The percentage scores were then categorized into three levels. Figure 1 shows that the majority of respondents have moderate knowledge about Chinese herbal tea $(51.23 \%)$.

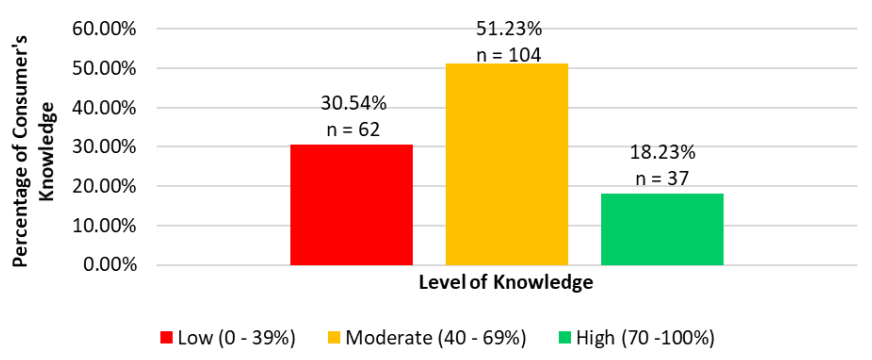

Figure 1. Level of consumers' knowledge towards Chinese herbal tea

The mean score for overall consumers' knowledge score and attitudes towards Chinese herbal tea was $\mathrm{M}=9.71$, S. $\mathrm{D}=4.389$ (min. score $=0$; $\max$. score $=20$ ) and $\mathrm{M}=3.54$, S.D. $=0.600(1=$ strongly disagree to $5=$ strongly agree) respectively. This result implies that consumers in Kedah are having moderate knowledge towards Chinese herbal tea. However, it may not be possible to extrapolate the results to the general population since the sample size was selected following a convenience sampling, and bias cannot be completely excluded as most of the participants were those who used Chinese herbal tea (Suleiman, 2014). Knowledge towards Chinese herbal tea is very important since it will continue to be passed down from generation to generations since many consumers believed that it was safe to consume. Furthermore, it is crucial that consumers should understand and knowledgeable of the function and nutritional composition of Chinese herbal tea as many trace elements play significant roles in the formation of active constituents responsible for the medicinal or curative properties in human (Law and Soon, 2013). Besides that, consumers' attitude towards Chinese herbal tea was rated $3.54 \pm 0.60$, indicating consumers have a moderate attitude towards Chinese herbal tea. This could be because there were many varieties of Chinese herbal tea available in the market and each of them is said to have a specific therapeutic or medicinal benefit to human health however consumers have limited scientific evidence of that claim (Liu, et al., 2013 and Ravikumar, 2014).

\subsection{Comparison of consumers' knowledge score among socio-demographic profiles}

Independent t-test and one-way ANOVA were used to compare consumers' knowledge score between sociodemographic profile such as gender, races, age, marital status, educational level, employment status and estimated current monthly household income. Table 2 shows the comparison of consumers' knowledge towards Chinese herbal tea between socio-demographic profiles.

Result revealed no statistically significant difference for comparison of knowledge score among sociodemographic profile of gender, age, marital status, educational level and employment $(\mathrm{p}>0.05)$. However, there was a significant difference in knowledge score between race $(p=0.033)$. These results can be supported by Law and Soon (2013) who reported no statistical significant difference for the knowledge score between socio-demographic characteristics of age $(\mathrm{t}=0.069, \mathrm{p}=$ 0.945), occupation $(\mathrm{t}=0.271, \mathrm{p}=0.786)$ and education level $(\mathrm{F}=2.230, \mathrm{p}=0.109)$. The comparison of knowledge with races was analysed using one-way ANOVA, the result showed that Chinese consumer had higher knowledge score towards Chinese herbal tea $(\mathrm{M}=10.02$, S.D. $=4.25)$ as compared with non-Chinese $(\mathrm{M}=8.32$, S.D. $=4.79)$ at $\mathrm{p}<0.05$. The result can be supported by Hassali et al. (2009) who reported that Malays' knowledge among all ethnic groups was poor especially the knowledge on the side effects of herbal beverages (Hassali et al., 2009). However, this situation may be caused by different ethnicity, culture and habits as Chinese herbal tea was usually consumed by Chinese and the knowledge was passed down from generation to generations, thus non-Chinese had lower chances to 
Table 2. Mean scores of socio-demographic profile on consumers' knowledge towards Chinese herbal tea

\begin{tabular}{|c|c|c|c|c|c|}
\hline \multicolumn{2}{|r|}{ Knowledge } & \multirow{3}{*}{$\begin{array}{c}\mathrm{n} \\
82 \\
121 \\
\end{array}$} & \multirow{3}{*}{$\begin{array}{c}\text { Mean } \pm \text { SD } \\
10.05 \pm 4.33 \\
9.48 \pm 4.43\end{array}$} & \multirow{3}{*}{$\begin{array}{c}\mathrm{F} / \mathrm{t} \text { value } \\
0.907\end{array}$} & \multirow{3}{*}{$\frac{p \text {-value }}{0.792}$} \\
\hline Gender & Male & & & & \\
\hline Gender & Female & & & & \\
\hline \multirow{2}{*}{ Race } & Chinese & 166 & $10.02 \pm 4.25$ & \multirow{2}{*}{4.585} & \multirow{2}{*}{0.033} \\
\hline & Non- Chinese & 37 & $8.32 \pm 4.79$ & & \\
\hline \multirow{5}{*}{ Age } & $18-25$ years old & 69 & $9.58 \pm 3.88$ & \multirow{5}{*}{1.261} & \multirow{5}{*}{0.287} \\
\hline & $26-35$ years old & 21 & $8.76 \pm 5.33$ & & \\
\hline & $36-45$ years old & 30 & $8.73 \pm 5.06$ & & \\
\hline & $46-55$ years old & 47 & $10.15 \pm 3.53$ & & \\
\hline & 56 years old and above & 36 & $10.75 \pm 5.04$ & & \\
\hline \multirow{3}{*}{ Marital status } & Single & 87 & $9.61 \pm 4.46$ & \multirow{3}{*}{0.119} & \multirow{3}{*}{0.888} \\
\hline & Married & 107 & $9.83 \pm 4.42$ & & \\
\hline & Divorced/ Widowed & 9 & $9.22 \pm 3.73$ & & \\
\hline \multirow{6}{*}{ Education Level } & PMR/SPM or lower & 81 & $10.56 \pm 4.60$ & \multirow{6}{*}{1.999} & \multirow{6}{*}{0.08} \\
\hline & STPM & 22 & $8.50 \pm 4.27$ & & \\
\hline & Diploma & 40 & $8.20 \pm 4.03$ & & \\
\hline & Degree & 58 & $10.00 \pm 4.17$ & & \\
\hline & Master/ Ph. D & 1 & $11.00 \pm 0.00$ & & \\
\hline & Others & 1 & $10.00 \pm 0.00$ & & \\
\hline \multirow{5}{*}{ Employment Status } & Employed & 109 & $9.71 \pm 4.52$ & \multirow{5}{*}{0.333} & \multirow{5}{*}{0.855} \\
\hline & Not working/ housewife & 16 & $9.19 \pm 5.17$ & & \\
\hline & Self-employed/ Own business & 20 & $9.35 \pm 4.89$ & & \\
\hline & Retired & 24 & $10.58 \pm 4.28$ & & \\
\hline & Student & 34 & $9.56 \pm 3.40$ & & \\
\hline
\end{tabular}

Independent t-test was used for gender.

One-way ANOVA was used for races, age, marital status, educational level, employment status, and estimated current monthly income. *Significant at $\mathrm{p}<0.05$ by independent t-test / One-way ANOVA

expose to the knowledge of Chinese herbal tea (WachtelGalor and Benzie, 2011).

\subsection{Comparison of consumers' attitude with socio- demographic profiles}

Independent t-test and one-way ANOVA were used to compare consumers' attitude between sociodemographic profile such as gender, races, age, marital status, educational level and employment status. Table 3 depicts the comparison of consumers' attitude towards Chinese herbal tea between socio-demographic profiles.

A significant difference was recorded for consumers' attitude towards Chinese herbal tea between different age groups $(\mathrm{p}<0.05)$ while no statistical significant difference was found between attitude and other socio-demographic profiles. Respondents from 18 to 25 years old had a significant favourable attitude towards Chinese herbal tea than other ages. This may due to respondents in this age groups are more concerned with their own body health. They are full of curiosity and willing to try something new and different with a positive attitude. For the comparison of consumers' attitude towards Chinese herbal tea among other socio-demographic profile, which are gender, races, marital status, educational level and employment status showed no significant difference $(\mathrm{p}>0.05)$. The $\mathrm{p}$-value for that socio-demographic profile was ranged from 0.159 to 0.687 while the $\mathrm{F}$ or t-value was ranged from 0.163 to 1.858 . This can be concluded that Chinese herbal tea can be accepted by respondents with different gender, age groups, and marital status. The results indicating that consumers with different educational level and employment status do not affect the consumers' attitude towards Chinese herbal tea. Based on Table 4, students showed the highest mean score (3.67 \pm 0.48$)$ in comparison to consumers' attitude between groups of employment status. This result was similar to the study conducted in several universities in China which stated that with the total of 1181 valid respondents, $50 \%$ of undergraduate students had a positive attitude towards tea and like to drink tea. They would like to accept lower tea price, prefer quality to brand, and have a higher degree of approval in new methods of tea drinking and products (Li et al., 2013).

\subsection{Association of consumers' consumption of Chinese herbal tea and socio-demographic profiles}

Table 4 displays the chi-square and p-value between the consumers' consumption and each demographic profile. A significant association was found for the 
Table 3. Mean scores of socio-demographic profile on consumers' attitude towards Chinese herbal tea

\begin{tabular}{|c|c|c|c|c|c|}
\hline \multicolumn{2}{|r|}{ Attitude } & $\mathrm{n}$ & Mean $\pm \mathrm{SD}$ & $\mathrm{F} / \mathrm{t}$ value & p-value \\
\hline \multirow{2}{*}{ Gender } & Male & 82 & $3.59 \pm 0.70$ & \multirow{2}{*}{1.082} & \multirow{2}{*}{0.219} \\
\hline & Female & 121 & $3.50 \pm 0.51$ & & \\
\hline \multirow{2}{*}{ Race } & Chinese & 166 & $3.53 \pm 0.62$ & \multirow{2}{*}{0.163} & \multirow{2}{*}{0.687} \\
\hline & Non- Chinese & 37 & $3.57 \pm 0.53$ & & \\
\hline \multirow{5}{*}{ Age } & $18-25$ years old & 69 & $3.68 \pm 0.66^{\mathrm{a}}$ & \multirow{5}{*}{2.504} & \multirow{5}{*}{0.044} \\
\hline & $26-35$ years old & 21 & $3.39 \pm 0.58^{\mathrm{ab}}$ & & \\
\hline & 36 - 45 years old & 30 & $3.60 \pm 0.49^{\mathrm{ab}}$ & & \\
\hline & 46 - 55 years old & 47 & $3.35 \pm 0.55^{\mathrm{b}}$ & & \\
\hline & 56 years old and above & 36 & $3.54 \pm 0.59^{\mathrm{ab}}$ & & \\
\hline \multirow{3}{*}{ Marital status } & Single & 87 & $3.61 \pm 0.63$ & \multirow{3}{*}{1.858} & \multirow{3}{*}{0.159} \\
\hline & Married & 107 & $3.46 \pm 0.57$ & & \\
\hline & Divorced/ Widowed & 9 & $3.72 \pm 0.62$ & & \\
\hline \multirow{6}{*}{ Education Level } & PMR/SPM or lower & 81 & $3.51 \pm 0.56$ & \multirow{6}{*}{0.802} & \multirow{6}{*}{0.549} \\
\hline & STPM & 22 & $3.51 \pm 0.63$ & & \\
\hline & Diploma & 40 & $3.43 \pm 0.50$ & & \\
\hline & Degree & 58 & $3.65 \pm 0.71$ & & \\
\hline & Master/ Ph. D & 1 & $3.78 \pm 0.00$ & & \\
\hline & Others & 1 & $3.94 \pm 0.00$ & & \\
\hline \multirow{5}{*}{ Employment Status } & Employed & 109 & $3.55 \pm 0.65$ & \multirow{5}{*}{1.136} & \multirow{5}{*}{0.341} \\
\hline & Not working/ housewife & 16 & $3.39 \pm 0.56$ & & \\
\hline & Self-employed/ Own business & 20 & $3.54 \pm 0.51$ & & \\
\hline & Retired & 24 & $3.38 \pm 0.61$ & & \\
\hline & Student & 34 & $3.67 \pm 0.48$ & & \\
\hline
\end{tabular}

Independent t-test was used for gender.

One-way ANOVA was used for races, age, marital status, educational level, employment status,

and estimated current monthly income. *Significant at $\mathrm{p}<0.05$ by independent $\mathrm{t}$-test/One-way ANOVA. Different superscripts within rows indicated significantly difference mean at the 0.05 level in the post-hoc comparisons of Tukey's HSD test.

Table 4. Association of consumers' consumption of Chinese herbal tea between socio-demographic profile

\begin{tabular}{|c|c|c|c|}
\hline & & Chi Square $\left(\mathrm{x}^{2}\right)$ & p-value \\
\hline \multirow{4}{*}{ Gender } & Consumption & 0.541 & 0.763 \\
\hline & Period of Consuming & 8.219 & 0.042 \\
\hline & Money spent per month & 3.319 & 0.190 \\
\hline & Amount consumed per day & 6.221 & 0.101 \\
\hline \multirow{4}{*}{ Race } & Consumption & 19.244 & 0.000 \\
\hline & Period of Consuming & 25.456 & 0.000 \\
\hline & Money spent per month & 5.863 & 0.053 \\
\hline & Amount consumed per day & 4.512 & 0.211 \\
\hline \multirow{4}{*}{ Age } & Consumption & 1.943 & 0.746 \\
\hline & Period of Consuming & 18.169 & 0.006 \\
\hline & Money spent per month & 18.4 & 0.001 \\
\hline & Amount consumed per day & 8.672 & 0.193 \\
\hline \multirow{4}{*}{ Marital status } & Consumption & 2.409 & 0.661 \\
\hline & Period of Consuming & 11.836 & 0.066 \\
\hline & Money spent per month & 13.677 & 0.008 \\
\hline & Amount consumed per day & 6.403 & 0.380 \\
\hline \multirow{4}{*}{ Education Level } & Consumption & 7.173 & 0.305 \\
\hline & Period of Consuming & 11.952 & 0.216 \\
\hline & Money spent per month & 6.644 & 0.355 \\
\hline & Amount consumed per day & 2.34 & 0.985 \\
\hline \multirow{4}{*}{ Employment Status } & Consumption & 4.671 & 0.323 \\
\hline & Period of Consuming & 9.593 & 0.143 \\
\hline & Money spent per month & 9.919 & 0.042 \\
\hline & Amount consumed per day & 6.286 & 0.392 \\
\hline
\end{tabular}

Significant at $\mathrm{p}<0.05$ by Chi-square 
association of consumers' consumption and gender, race, age, marital status and employment status. There was a significant association found between periods of consuming with gender $(\mathrm{P}<0.05)$. Chen et al. (2016) showed that male consumption quantity is $10.1 \%$ higher than female. Similarly, Li et al. (2013) reported male students $(55.4 \%)$ like to drink tea more than female students $(48.4 \%)$ and the study narrated that no matter undergraduate students or common people, males are the mainstream group of tea drinking in China. Besides, Rezaee et al. (2016) found that the mean consumption of men was significantly higher tea consumption than women $(p<0.05)$ in a study in Isfahan, Iran. It is thought that humans are divided into Yin and Yang in Chinese traditional culture with the female belongs to Yin while the male belongs to Yang. Besides, the Yang is stronger than Yin, so Yang's body more easily gets heat and to more extent, the Yang which refers to male would consume Chinese herbal tea frequently to remove body heat (Wan, 2015).

Besides, a significant association was found between consumption and period of consuming with races. Chinese herbal tea consumption of a person with different races is influenced by tradition, and his or her external environment, such as household tea-drinking atmosphere, workplace, and locational factors (Chen et al., 2016). For instance, Chinese usually consume Chinese herbal tea as this habit is passed down from generation to generations, and they already familiar with it since young. Other races might not familiar with Chinese herbal tea. In addition, Chinese foods which are usually spicy had become the main factor that influences consumers on purchasing herbal beverages which can remove heat after eating spicy food (Chen et al., 2016).

Furthermore, there was a significant association between the money spent per month with marital status $(p<0.05)$. Marriage has a significant effect on tea consumption as the study indicates that married participants drank much tea than singles $(p<0.05)$. Adversely, the number of family members will not influence the average of tea consumption. It might due to the tradition of drinking tea is quite prevailing in families (Rezaee et al., 2016). However, another study revealed that having extra one more household member to drink tea was usually associated with a $6.6 \%$ of the increase in their annual tea consumption quantity (Chen et al., 2016).

There was no significant association between the consumers' consumption towards Chinese herbal tea with educational level $(\mathrm{p}>0.05)$. A positive relation between tea intake and educational level was reported by Razaee et al. (2016) and Sofuoqlu and Kavcar (2008). For employment status, there was a significant association found between money spent per month on Chinese herbal tea with employment status $(\mathrm{p}<0.05)$. The result was opposed with the study by Chen et al. (2016) which showed no significant associations were found between other occupations and tea consumption. Moreover, administrative personnel, retirees and common workers were loyal tea consumers, while students and soldiers may seldom drink tea (Li et al., 2013).

\section{Conclusion}

In conclusion, respondents were somewhat knowledgeable about Chinese herbal tea and its benefits and different age groups were found to have different knowledge and attitudes towards Chinese herbal tea. These findings are important for the government and non -government agencies in improvising and setting ready or new policies and regulations regarding complementary medicine and convey correct information and useful knowledge for the public by conducting several campaign or program to prevent the misunderstanding and misusing of Chinese herbal tea.

\section{Conflict of Interest}

The authors declare no conflict of interest.

\section{Acknowledgement}

High appreciation was given to the owner of selected Chinese Herbal Shop in Sungai Petani and respondents who have voluntarily participated in this study.

\section{References}

Ahmad, F., Zaidi, A.S., Sulaiman, N. and Majid, F.A. (2015). Issues and challenges in the development of the herbal industry in Malaysia. Prosiding Perkem, 10, 227- 238.

Amundsen, B. (2013). Fewer willing to participate in surveys. Retreived on September 8, 2017 from The Research Council of Norway website: https:// www.forskningsradet.no/en/Newsarticle/

Fewer_willing_to_participate_in_surveys/12539868 12629.

Chen, F., Li, S., Jiang, R. and Jiang, A. (2016). What factors are influencing tea consumption among Chinese urban residents? An empirical study. International Journal of Consumer Studies, 40(2), 249-254. https://doi.org/10.1111/ijcs.12249

Chinese Herb Tea. (2017). Retrieved on October 10, 2017 from Food Nation 2017 website: https:// foodnation2017.wordpress.com/2017/03/14/chineseherb-tea/

Daily, J.W., Yang, M., Kim, D.S. and Park, S. (2015). 
Efficacy of ginger for treating Type 2 diabetes: A systematic review and meta-analysis of randomized clinical trials. Journal of Ethnic Foods, 2(1), 36-43. https://doi.org/10.1016/j.jef.2015.02.007

Daly, M., Tai, C.J., Deng, C.Y. and Chien, L.Y. (2009). factors associated with ultilization of traditional Chinese medicine by white collar foreign workers living in Taiwan. BMC Health Services Research, 9 (10), 7. https://doi.org/10.1186/1472-6963-9-10

Department of Statistics Malaysia. (2010). Retrieved on October 10, 2017 from Department of Statistics Malaysia website: https://www.dosm.gov.my/v1/

Ghasemi, A. and Zahediasl, S. (2012). Normality tests for statistical analysis: a guide for non-statisticians. International Journal of Endocrinology Metabolism, 10(2), 486-489. https://doi.org/10.5812/ijem.3505

Glass, D.C., Kelsall, H.L., Slegers, C., Forbes, A.B., Loff, B., Zion, D. and Fritschi, L. (2015). A telephone survey of factors affecting willingness to participate in health research surveys. BMC Public Health, 15, 1017. https://doi.org/10.1186/s12889015-2350-9

Guilford, J.P. and Fruchter, B. (1973). Fundamental statistics in psychology and education. New York: McGraw-Hill.

Hassali, M.A., Khan, T.M., Shafie, A.A. and Nazir, M. (2009). Public knowledge about herbal beverages in Penang, Malaysia. Australasian Medical Journal, 1, 1-11. https://doi.org/10.4066/amj.2009.71

Lan, W., Lee, S.Y., Lee, M.X. and Tong, L. (2012). Knowledge, attitude, and practice of dry eye treatment by institutional Chinese physicians in Singapore. The Science World Journal, 2012, 1-9. https://doi.org/10.1100/2012/923059

Law, K.S. and Soon, L.K. (2013). Herbal medicines: Malaysian women's knowledge and practice. Evidence-Based Complementary and Alternative Medicine, 2013, 1-10. https:// doi.org/10.1155/2013/438139

Li, J., Lu, X., Jiang, M., Shao, W. and Zhou, J. (2013). Survey and analysis on undergraduate tea consumption and attitude towards tea consumption. Asian Agricultural Research, 5(5), 118-120.

Li, X. and Zhu, X. (2016). Tea: types, production, and trade. The Encyclopedia of Food and Health, 5, 279282. https://doi.org/10.1016/B978-0-12-3849472.00684-X

Liu, Y., Ahmed, S. and Long, C. (2013). Ethnobotanical survey of cooling herbal drinks from Southern China. Journal of Ethnobiology and Ethnomedicine, 9, 1-7. https://doi.org/10.1186/1746-4269-9-82

Matic, I., Juranic, Z., Zdunic, G. and Godevac, D. (2013). Chamomile and marigold tea: chemical characterization and evaluation of anticancer activity. Phytotherapy Research, 27(6), 852-858. https://doi.org/10.1002/ptr.4807

Nekesa, M.D. (2012). Nutritional knowledge, attitudes and practices of primary caregivers of home grown school feeding programme pupils at Sauri Millenium Village, Siaya-Kenya. Nairobi, Kenya: Kenyatta University, MSc. Thesis.

Noguchi-Shinohara, M., Yuki, S., Dohmoto, C., Ikeda, Y., Samuraki, M., Iwasa, K. and Nakamura, H.A. (2014). Consumption of green tea, but not black tea or coffee is associated with reduced risk of cognitive decline. PLoS ONE, 9(5), 1-8. https:// doi.org/10.1371/journal.pone.0096013

Nunnally, J.C. and Bernstein, I.H. (1994). The assessment of reliability. Psychometric Theory, 3, 248-292.

Ravikumar, C. (2014). Review on Herbal Teas. Journal of Pharmaceutical Sciences and Research, 6(5), 236238.

Rezaee, E., Mirlohi, M., Hassanzadeh, A. and Fallah, A. (2016). Factors affecting tea consumption pattern in an urban society in Isfahan, Iran. Journal of Education Health Promotion, 5, 13. https:// doi.org/10.4103/2277-9531.184568

Sofuoqlu, S. and Kavcar, P. (2008). An exposure and risk assessment for fluoride and trace metals in black tea. Journal of hazardous materials, 158(2-3), 392400.

Suleiman, A.K. (2014). Attitudes and beliefs of consumers of herbal medicines in Riyadh, Saudi Arabia. Journal of Community Medicine and Health Education, 4, 269. https://doi.org/10.4172/21610711.1000269

Teijlingen, E.V. and Hundley, V. (2002). The importance of pilot studies. Nursing Standard, 16 (40), 33-36.

Wachtel-Galor, S. and Benzie, F. (2011). Herbal medicine: biomolecular and clinical aspects. $2^{\text {nd }} e d$. USA: CRC Press.

Wan, S. (2015). Chinese Herbal tea brand positioning strategy: case study: Wong Lo Kat Herbal Tea. Finland: Savonia University of Applied Sciences, BSc. Thesis.

Wilson, M. (1993). Herbal tea consumption during pregnancy. University of Wollongong Thesis Collection, 1-75.

Yamane, T. (1967). Statistics, An Introductory Analysis. New York: Harper and Row.

Zemestani, M. and Rafraf, M. (2016). Chamomile tea improves Glycemic Indices and antioxidants status in patients with type 2 diabetes mellitus. Nutrition, 32(1), 66-72. https://doi.org/10.1016/ j.nut.2015.07.011 